flaps, methods of combatting shock, etc. The chapter on the eye is relatively short, running to only eighteen pages, and dealing with the lids and lacrymal apparatus. The cure of cicatricial ectropion by free skin graft is dealt with in detail and excellent accounts are given of Greeves' operation for ptosis, and of Savjn's modification of Lexer's procedure. The diagrams illustrating the latter two are particularly clear and easily comprehended, more so than the photographic illustrations employed in the descriptions of some of the other operations.

This is a book which ophthalmic surgeons may well find useful, because in addition to dealing with local conditions, it contains a wealth of information about modern methods employed in plastic surgery generally, of a kind not usually available in ordinary text books. It has the advantage of not being a mere compilation of the writings of others, but embodies the author's practical experience. The descriptions of treatment are, therefore, concise and easily followed.

The author is to be congratulated upon the production of such a useful volume, and the publishers on its excellent format.

\title{
CORRESPONDENCE
}

\section{VISIBLE EMBOLI IN RETINAL ARTERIES}

To the Editors of THE BRITISH JOURNAL OF OPHTHALMOLOGY.

DEAR SIRS,-With reference to the article on "Visible Emboli in the Retinal Arteries" in the January number of Brit. Jl. of Ophthal.; there has been omitted from the list of clinical references a case reported by me in The Ophthalmoscope, Vol: X, 1912, p. 370a case very similar to one of those now reported. The embolism occurred in a male, aged 31 years, in whom there was evidence of cardiac valvular disease. Sudden blindness occurred in the right eye. The patient rubbed the eye vigorously, and shortly afterwards, the sight returned in the upper half of the visual field. The embolus which was visible, had been displaced into the superior branch of the central retinal artery. A somewhat crude drawing made by me at the time illustrates my report, together with charts of the visual field in which a considerable recovery took place with restoration of vision nearly full 6/6. This case demonstrated the value of immediate massage in such cases, first pointed out, I believe, by my late colleague, Dr. E. Wood-White of the Birmingham and Midland Eye Hospital many years ago now. That these cases of true 
embolism are rare, there is no doubt. In close on forty years of extensive ophthalmology, I have seen only two undoubted cases.

Yours, etc.,

BIRMINGHAM,
Januaty 22, 19+4.

\section{TONOMETRY}

To the Editors of THE BRITISH JOURNAL OF OPHTHALMOLOGY.

DEAR SIRS,-While it must be conceded that tonometers do not give an absolute millimetric measure of the intra-ocular pressure, and are subject to both collective and individual inaccuracies, yet as the three in common use in this country (those of Bailliart, Schiötz, and McLean) have common maxima at $140 \mathrm{~mm}$., the figure of $212 \mathrm{~mm}$. mentioned in the annotation "Tonometry" last month, must not only be regarded as "truly majestic," but also slightly unique.

On the other hand, I venture to doubt if the "tactus eruditus," on which our predecessors placed, and many contemporaries still place so great reliance, exists in the sense in which the words are understood:

I would not deny the existence of a "tactus non omnino rudis," but I would imply by this term that it lacks the delicacy required to eludicate a case, the nature of progress of which is doubtful from other considerations.

Such doubt is in keeping with the trend in medicine to regard refinements of diagnosis depending on digital expertise, with increasing scepticism. Palpation of the pulse, and percussion of the chest both provide examples of this.

My doubt in this particular case, however, did not spring from general considerations, but from checking by tonometer the digital estimations, first of others, and then myself.

Assuming on earlier teaching, and on higher authority (PriestleySmith) that the tonometer was at least a more delicate indicator of deviations from the normal intra-ocular pressure in the same eye from time to time, and in two eyes in the same person simultaneously, than the fingers, I decided that not only did I not possess the tactus eruditus, but that there are others almost equally; though less consciously unfortunate.

On enquiry, Professor Loewenstein tells me that he came to the same conclusion with regard to himself, in the same way.

If one rejects the tonometer as being an uncertain check, there is still another way in which the matter can at least be partly testedthat adopted by Harrison Butler: (Ref. Brit.Jl. of Ophthal.; p. 116, 